\title{
TRÊS LIÇÕES DE FILOSOFIA DA EDUCAÇÃO
}

\author{
WaLter OMAR Kohan*
}

\begin{abstract}
RESUMO: O presente trabalho busca pensar o valor de $O$ mestre ignorante como exercício de filosofia da educação, em particular contrapondo-o a um modo, dominante, de exercer esse saber no seio de nossas instituiçōes. Trata-se de uma história singular, pela qual todo mestre pode se perguntar por que e para que ensina; e, o que é ainda mais importante, pela qual pode questionar-se que diabos está fazendo consigo mesmo e com os outros, a cada vez que se veste de mestre em uma sala de aula. Depreendemos, desse exercício, três liçōes: a) o mais natural, evidente e aceito socialmente acaba sendo, filosoficamente, o mais problemático; b) somente pelo paradoxo, entranhados no lodo paradoxal, podemos encontrar algum sentido na educação; c) só há uma educação que vale a pena: a que emancipa (sem emancipar). Quem não deixa que os(as) outros(as) se emancipem embrutece.
\end{abstract}

Palavras-chave: Filosofia da educação. Emancipação. Sócrates.

\section{THREE LESSONS OF PHILOSOPHY OF EDUCATION}

ABSTRACT: This paper aims to rethink the value of The ignorant schoolmaster as an exercise in the philosophy of education, especially as counterpoised to the way philosophy of education is presently exercised in our institutions. It is a singular story, by which teachers can ask why and for what they teach and, even more meaningfully, they can put into question what they are doing with themselves and with their students each time they enter a classroom. We can take three lessons from this exercise: a) that the most natural, evident and socially accepted pedagogical ends appear to be the most philosophically problematic; b) that only through paradox -

Professor Titular de Filosofia da Educação da Universidade do Estado do Rio de Janeiro (UERJ).E-mail: walterk@uerj.br ou walterko@uol.com.br. Agradeço a Lílian do Valle pela tradução deste texto.

Educ. Soc., Campinas, vol. 24, n. 82, p. 221-228, abril 2003

Disponível em <http://www.cedes.unicamp.br> 
through being thrown into the paradoxical mud - we can find some real meaning in education; c) that the only education worthy of the name liberates without liberating. The one who does not allow for the liberation of the others oppresses.

Key words: Philosophy of education. Emancipation. Socrates.

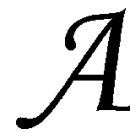

filosofia da educação ocupa um lugar pouco interessante no universo acadêmico, ao menos em nossos países hispanoamericanos. Depreciada na imensa maioria dos departamentos de filosofia das instituições de formação superior, acolhida nos de educação, costuma ser matéria obrigatória nos cursos de formação de mestres. Tornada, assim, muitas vezes, o único espaço de contato com a filosofia durante todo o processo de formação, seus docentes, programas e bibliografia costumam manter, no melhor dos casos, um caráter enciclopédico, totalizador e fundacionista. Em todo o caso, o repertório não parece muito variado: aqui, a história das idéias filosóficas sobre a educação; lá, correntes do pensamento filosófico sobre a educação; ou, então, o estudo das divisões mais ou menos claras do saber pedagógico, segundo orientações bastante clássicas do conhecimento filosófico: um pouco de epistemologia, outro tanto de axiologia e de ontologia, usadas para explicar o fenômeno educativo. Dessa forma, o aluno mais afortunado poderá compreender, com a ajuda de um mestre explicador, um saber filosófico, histórico ou sistemático, sobre a educação. Aprenderá a distinguir, com as explicaçóes que recebeu, escolas e orientaçôes pedagógicas, períodos, conceitos e categorias, que habilmente relacionará às correntes de pensamento já instituídas. Para os menos afortunados, essas mesmas explicações funcionarão, muito mais simplesmente, como uma espécie de doutrinação educativa, que os infundirá, brutal ou delicadamente, da firme crença nos fins, nos valores e nos ideais que deverão passar a perseguir.

Esses modos de ensinar a filosofia da educação não estão isentos de pressupostos sobre o significado e sentido de ensinar e aprender a filosofia, assim como sobre suas relações com a educação. Trata-se, basicamente, de transmitir um certo saber instituído, predeterminado, que permitirá uma compreensão mais "crítica" do fenômeno educacional ou, simplesmente, compreender a "verdadeira" missão da filosofia na educação. Nas versões mais aggiornadas, o saber filosófico toma a forma de conteúdos conceituais ou atitudinais que contribuirão para a aquisição das habilidades ou competências de pensamento crítico, por parte do(a)s futuro(a)s profissionais da educação. 
Nesse horizonte, um texto como $O$ mestre ignorante decerto não encontra posição de comodidade, mas enfrentará resistências e esquivanças. Afinal, não é mais do que uma história, dirão alguns profissionais. Uma fábula, um conto, uma experiência. Que lugar poderá manter esta história, objetarão certos eruditos, na longa galeria das tradições rigorosas de ensino, com seus métodos mais ou menos consolidados de transmissão de saber? Possivelmente, entre uns e outros, haverá os que se disporão a admitir algum valor literário na narrativa de Rancière, considerando-a como uma bela história. Dificilmente, porém, algum espaço lhe será reservado nas instituições onde se ensina formalmente a filosofia da educação. No mais, mesmo os que se atreverem a fazê-lo deverão arcar com o que advertia o próprio Rancière: não se trata de institucionalizar nada, inclusive porque "jamais um partido, um governo, um exército, uma escola ou uma instituição emancipará uma única pessoa”. (2002, p. 142).

No entanto, é nesse confronto, no abismo entre duas formas opostas de entender a filosofia da educação que pretendo situar minha intervenção. Importa-me explorar em que sentido a leitura de $O$ mestre ignorante pode se constituir em uma experiência formativa interessante, sobretudo para aqueles(as) que já abraçam, ou se preparam para abraçar o ofício de ensinar; e, ao fazê-lo, suponho que poderei contribuir também para problematizar o modo habitual de se entender a filosofia da educação, particularmente em nossas instituições universitárias. De resto, se a empreitada supera de muito a questão puramente disciplinar, é porque o que está em jogo, quando se lê $O$ mestre ignorante, é o próprio sentido que assume para nós, que trabalhamos em educação, o exercício do pensamento.

Assim, considero que um dos principais méritos da obra que Jacques Rancière dedicou à matéria está na graça e na vitalidade com que propõe uma forma renovadora de exercer a filosofia da educação. Nada mais, enfim, do que um exercício. Pensamento vivo e em ato. Nada de esquemas, classificações, generalizações. Filosofia em ato, experiência de interrogação, irrenunciável, sobre a própria experiência. Exercício singular que dá lugar a um pensamento singular. Singular, como diferente e como comum, por ser a história de um mestre e não de um indivíduo, uma história cuja significação não reside nas particularidades de Jacotot, desse ou daquele mestre, senão de um mestre que encarna, em si mesmo, todo mestre que dele queira servir-se para se perguntar por que e para que ensina; e, o que é ainda talvez mais importante, para questionar-se que diabos está fazendo consigo mesmo e com os outros, a cada vez que se veste de mestre em uma sala de aula. 
Por isso, como o exercício de um mestre que se interroga a si mesmo, a leitura de $O$ mestre ignorante pode ser um belo trabalho de emancipação, em um dos sentidos que Rancière confere à palavra, em seu livro: forçar uma capacidade ignorada ou negada a desenvolver todas as conseqüências desse reconhecimento. Exercício emancipatório de leitura que nos força a pôr em questão o modo e o sentido com que ensinamos, as forças que nos movem a fazê-lo, as apostas políticas que, conscientemente ou não, afirmamos em nossa prática. Emancipatório é o exercício, se nos permite, ao final das contas, de educar sem subestimar ninguém - começando por não subestimarmos a nós próprios.

De tal forma que, ainda que se possam distinguir em $O$ mestre ignorante algumas teses de peso, substantivas (o princípio da igualdade das inteligências; o "existo, ergo penso"; a explicação como arte da distância; a relação entre vontade e inteligência; o estatuto político e filosófico da igualdade etc.), não reside aí o mais interessante da aposta de Rancière. Ao contrário, são essas teses polêmicas, sumamente discutíveis, de aceitação bastante difícil, em vista da forma ostensivamente radical e provocativa com que são expostas. Decididamente, esse livro não foi feito para suscitar acordos ou consensos. Seria estranhamente contraditório valorizar sua força explicadora.

Ao contrário, a potência de $O$ mestre ignorante parece estar situada nos desacordos que supóe e provoca, no trabalho de pensamento que desencadeia, como expressão solitária, inaudita, dissonante e, apesar de tudo, suficientemente forte para interrogar uma realidade que desconsidera suas principais proposiçôes ou, no melhor dos casos, as ignora. A força da narrativa não está, portanto, na originalidade das teses que avança, senão na radicalidade da experiência que provoca.

Pois - admitamos de uma vez por todas - todos, em educação, alguns um pouco mais, outros um pouco menos, afirmamos o que Jacotot nega e desconsideramos o que mais valoriza. Partimos da desigualdade. Somos formados para explicar o que aprendemos (a desigualdade). Fomos explicados e, assim, explicamos. Acentuamos a desigualdade. Voltamos a explicar. Tudo, então, continua como dantes: não podemos, claro, sair do círculo do embrutecimento. Seguimos explicando. Pela vida. Embrutecemos. Nos embrutecemos.

Jacotot nos expõe a nosso contrário. Propicia (força?) um encontro com o que não praticamos e não valorizamos. E, por essa via, nos leva a voltar a pensar sobre o modo e sobre o sentido daquilo que fazemos. Não 
se trata, é claro, de "transformar" o modo como pensamos o ensinar e o aprender. Tampouco está em questão deixar de fazer o que fazemos, para fazer o oposto. Mas, inversamente, interessa pensar por que essa forma de educação emancipadora se encontra nos antípodas daquilo que se tornou tão evidente em nossas teorias e nossas práticas. Importa pensar por que não pudemos pensar que estamos embrutecendo e nos embrutecendo. Contudo, por mais que definitivamente não seja o caso, aqui, de seguir os preceitos de um novo método, nem de copiar um modelo, aos poucos vai-se tornando impossível continuar pensando o que pensávamos e fazendo o que fazíamos.

Desse modo, a filosofia da educação se faz exercício que não explica, não legitima, não consolida. Escapa à tentação de constituirse como lei e como verdade. Pelo contrário: dessacraliza, polemiza, interroga. Impede que ensinemos da forma como ensinávamos, que pensemos a educação da forma como a pensávamos, que sejamos os mesmos educadores que éramos. Permite-nos pensar, ser e ensinar de outro modo. Essa é, no meu entender, a força emancipadora de $O$ mestre ignorante. Esse é seu valor filosófico e pedagógico: mergulhar o leitor em um círculo do qual só pode sair valendo-se de sua própria inteligência. Disruptor dos círculos do óbvio, do normal e do inquestionado que habita em nós, esse outro círculo faz da emancipação uma questão de sobrevivência.

\section{A inflexível igualdade do exercício: o anti-Sócrates}

Esse exercício de filosofia da educação tem como ponto inflexível, irrenunciável, a igualdade - princípio, opiniāo, pressuposto, algo que não tem valor de verdade, que não pode ser demonstrado, mas sem o que não pode se fundar, na perspectiva de Rancière, uma educação radicalmente diferente daquela dominante, e que segue a lógica da superioridade-inferioridade.

Para Rancière, quando a igualdade é colocada como objetivo, ou finalidade, e não como princípio, afirma-se a lógica desigualitária que a nega. Precisamente na relação com a igualdade define-se o caráter conservador, ou revolucionário de um(a) educador(a). Será liberador(a) aquele que, partindo da igualdade, a verifique e permita, assim, perceber a potência não inferior de toda inteligência. Qualquer outra relação com a igualdade que não seja a de princípio é, para Rancière, embrutecedora. 
Dessa forma, a igualdade é, ao mesmo tempo, condição e limite para um modo de praticar a filosofia da educação: por um lado, é aquilo que, na ótica de Rancière, permite pensar filosoficamente a educação; mas é também aquilo sem o que não se pode pensar a educação como tal. A igualdade é o axioma do pensamento, seu fundo, o não-filosófico que abre espaço para a filosofia. Paradoxo da igualdade.

Talvez seja interessante apreciar o peso da figura de Sócrates nesse exercício. Sabemos o papel singular, fundador, paradoxal, de Sócrates em nossa tradição de filosofia da educação. Singular porque incomparável, fundador porque inaugural, paradoxal porque, sendo reconhecido por todos como o primeiro filósofo da educação, exercita uma filosofia da educação contrária a de seus próprios celebrantes.

A tentação de assimilar o mestre ignorante a um Sócrates modernizado é grande, fácil, imediata. Rancière arremete, no entanto, contra o ídolo, desfazendo-o política e filosoficamente. Não perdoa sua veia desigualitária. Reprova sua paixão pela superioridade e inferioridade. Enfim, por trás de sua declaração de ignorância, Sócrates, o divino, dá fé ao oráculo: pensa que é o mais sábio, na pólis, e que sua tarefa consiste, justamente, em mostrar aos outros o pouco valor de seu saber, sobretudo quando comparado ao saber do próprio Sócrates.

Sócrates não é um mestre ignorante; é um sábio mestre de sua ignorância. Pretende impor, como todos os mestres da tradição, seu saber aos demais. $\mathrm{O}$ modo como Sócrates oculta o caráter embrutecedor de seu saber o torna mais sofisticado e dissimulado. E, portanto, mais perigoso.

Todos os que se entretêm com Sócrates, nos Diálogos de Platão, têm algo - o mesmo - a aprender. Não importa se, de fato, o diálogo chega a um saber conclusivo ou a uma aporia: todos devem aprender que aprender com a filosofia, com Sócrates, significa deixar de saber o que se pensava saber; todos devem saber que, para aprender o saber filosófico, é preciso acompanhar o caminho do mestre, deixar-se levar por ali onde o outro, aquele que sabe, deseja ir.

O escravo do Mênon é emblemático: não só não aprende nada por si, mas aprende que, para aprender, necessita de alguém que o leve pelas mãos: alguém como Sócrates, que bem sabe aquilo que ele, de todo modo, deveria aprender. $\mathrm{O}$ escravo também aprende sua ignorância, e a sabedoria do mestre: aprende que, para aprender, deve seguir outra inteligência, a do mestre. Assim, o diálogo com Sócrates aprofunda sua escravidão. Reforça-a, embrutecendo-no. 
Mas, o que é ainda pior, Sócrates esconde sua paixão embrutecedora debaixo de uma aparência libertadora. Seu disfarce, suas máscaras, a maneira como oculta sua paixão desigualitária o tornam mais perigoso. Contudo, para qualquer observador interessado na emancipação, fica claro que Sócrates embrutece: não pergunta o que ignora, para saber e para instruir-se, mas sempre pergunta aquilo que sabe, para que os outros "recordem" o que ele já sabe e, sobretudo, para que todos verifiquem que somente ele detém o saber que vale alguma coisa. Sacrílego saber da ignorância. Dizia que nunca buscou ensinar, mas sempre soube, de antemão, aquilo que os outros deveriam saber. Indigno saber da ignorância. Amante do saber da ignorância, pretendeu que todos amassem seu saber. Perverso uso da ignorância. Seguidor do oráculo, valorizou unicamente o saber que legitimava seu próprio saber. Embrutecedora política do desprezo.

As lições de uma leitura

Ainda essa vez, Rancière nos remete ao que queremos ou não queremos ser, como mestres. Pois, que mestre jamais pretendeu ser como Sócrates? Quem jamais se deleitou com sua mentirosa ignorância? Quem nunca quis vestir o mesmo disfarce do perguntador que não pergunta? Ainda essa vez, situando-se nos antípodas do sentido comum pedagógico, Rancière nos faz mergulhar em um círculo que somente podemos romper por nós. Primeira lição (filosófica) do ignorante: o mais natural, evidente e aceito pedagógica e socialmente acaba por se mostrar o mais problemático filosoficamente.

Ao mesmo tempo em que $O$ mestre ignorante nos põe face ao incômodo de perceber nosso contrário, problematizando nossas obviedades, acompanha-nos na abertura de sentido que propicia a percepção do paradoxo, permitindo-nos pensar o caráter constitutivamente paradoxal do ato pedagógico. Pois Jacotot nos mostra, por exemplo, como a ignorância é, a uma só vez, necessária e impossível para o ensinar, do mesmo modo que o axioma igualitário e a emancipação são necessários e impossíveis para a ordem social. Algo que só pode ensinar quem nada tem a ensinar. Porque ensinar de verdade, diria Rancière, não pode significar nada que tenha a ver com transmitir, senão com permitir que o outro se emancipe. Segunda lição (educacional) do ignorante: somente pelo paradoxo, entranhados no lodo paradoxal, podemos encontrar algum sentido na educação. 
Finalmente, a lição da emancipação de um mestre que se emancipa a si próprio, que ensina com seu próprio método, isso é, sem método. Que ensina também que a emancipação não tem a ver com um conteúdo, uma doutrina ou um conhecimento. Que ninguém pode emancipar ninguém. Um mestre que escreve sua própria história, para que os outros a leiam. E outro mestre lê a história, reflete sobre ela e a relata para que outros(as) mestres a pensem. E se emancipem, na contradição e no paradoxo. Afinal, um ser humano pode o que pode qualquer ser humano. Terceira lição (política) do mestre ignorante: só há uma única educação que vale a pena - a que emancipa (sem emancipar). Quem não deixa que os(as) outros(as) se emancipem, embrutece.

Três lições para a filosofia, a educação e a política. Lição de política para a filosofia da educação. Lição de filosofia para a política da educação. Lição de educação para a política da filosofia. Lições de uma experiência de filosofia da educação.

Recebido e aprovado em fevereiro de 2003.

\section{Referência bibliográfica}

RANCIÈRE, J. O mestre ignorante. Cinco lições sobre a emancipação intelectual. Trad. Lílian do Valle. Belo Horizonte: Autêntica, 2002. (Série: Educação. Experiência e sentido). 